\title{
ALEGORIA MEDIEVAL: ONDE SE SITUA A POESIA DE CHARLES D'ORLÉANS?
}

\author{
Luana C. Benedetto
}

Resume

La présente étude a pour objet d'analyser brièvement l'allégorie, la personnification, la métaphore, telles qu'elles se présentent dans l'oeuvre de Charles d'Orléans, poète français du $\mathrm{XV}^{\mathrm{e}}$ siècle. Pour ce faire, on considère la démarche allégorique dès son origine dans l'antiquité classique, les divers genres d'allégories et la tradition allégorique médievale dans laquelle Charles d'Orléans s'inscrit. Il s'agit d'une tradition amorcée par le Roman de la Rose et qui plonge ses racines dans l'oeuvre d'Alain de Lille. En outre, on fait une étude succinte du symbole et de la synecdoque, en examinant les vues de Curtius, Huizinga, Hansen, Eco, Greimas, Dubois, Lausberg et Ricoeur, parmi d'autres.

Mots-clés:Moyen Âge, allégorie, personnification, métaphore, poésie.

Resumo

Este estudo tem o objetivo de analisar brevemente a alegoria, a personificação e a metáfora, do modo como se apresentam na obra de Charles d'Orléans, poeta francês do século XV. Para tanto, consideram-se a atitude alegórica desde sua origem na antiguidade clássica, os diversos tipos de alegoria e a tradição alegórica medieval na qual Charles d'Orléans se insere. Trata-se de uma tradição iniciada pelo Romance da Rosa, cujas raízes mergulham na obra de Alain de Lille. Além disso, faz-se um estudo sucinto do símbolo e da sinédoque, discutindo as visões de Curtius, Huizinga, Hansen, Eco, Greimas, Dubois, Lausberg e Ricoeur, entre outros. Palavras-chave: Idade Média, alegoria, personificação, metáfora, poesia.

Rondeau CCXXV

En la forest de Longue Actente, Par vent de Fortune Dolente, Tant y voy abatu de bois Que, sur ma foy, je n'y cognois A present de voye, ne sente.

Pieça, y pris joyeuse rente, Jeunesse la payoit contente, Or n'y ay qui vaille une nois, En la forest [de Longue Actente.] 
Vieilesse dit, qui me tourmente :

Pour toy n'y a pesson, ne vente, Comme tu as eu autresfois ;

Passez sont tes jours, ans et mois ; Souffize toy et te contente,

En la forest [de Longue Actente.]

O estudo das figuras presentes na poética de Charles d'Orléans concentra-se obrigatoriamente na chamada "personificação", tão marcante é ela nessa obra. Para bem entendê-la é imprescindível um estudo da alegoria em geral, com o fim de estabelecer os elos existentes entre os dois recursos, procurando responder às seguintes perguntas: a) o que ambas têm em comum? e b) é possível classificar como alegorias, pura e simplesmente, as figuras utilizadas por Charles d'Orléans?

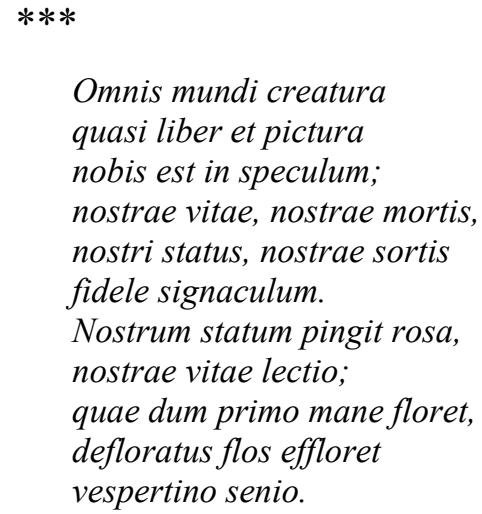

(Rhythmus alter, PL 210, col. 579) ${ }^{1}$

Não é apenas por sua beleza incontestável que transcrevemos acima esses versos latinos, mas porque, por um lado, eles constituem uma verdadeira síntese de certa atitude alegorizante medieval e, por outro, apresentam o mesmo tema - a rosa - que mais tarde servirá de eixo condutor do famoso poema de Guillaume de Lorris e Jean de Meung, Le roman de la rose, que, por sua vez, tanta influência exercerá sobre Charles d'Orléans e sobre várias gerações de poetas franceses. Esses versos latinos são atribuídos a Alain de Lille (ou Alanus ab Insulis), escritor de expressão filosófica e literária que teria nascido por volta de 1120 e morrido em torno de 1202-1203. Segundo consta, era dono de vasta cultura, impregnada do platonismo de Calcídio e de Macróbio, mas também de Boécio, Asclépio e da tradição das artes liberais. Teria sido "o último e supremo porta-voz da tradição latina e romana da filosofia grega, derradeiro testemunho da aetas boetiana (era de Boécio). Esses dados não são apenas enciclopédicos, como veremos adiante. A tradução literal de tais versos é:

Toda criatura do universo como um livro ou uma pintura serve-nos de espelho;

fiel signo

de nossa vida, de nossa morte,

de nosso estado, de nossa sorte.

\footnotetext{
${ }^{1}$ Apud Eco, Umberto, 1987, p. 90.
} 




A primeira parte, que vai do início a "sorte", afirma um pressuposto, uma premissa: o destino do homem está retratado em tudo o que há no universo, ou, em outros termos, qualquer criatura do universo pode servir de signo da sorte humana. A segunda parte, que vai de "nosso estado" ao fim, é conseqüência e ilustração dessa premissa: se toda criatura do universo é signo da sorte humana, tomemos a rosa, que sintetiza a nossa trajetória: desabrocha(mos) ao amanhecer, floresce(mos) durante o dia e perde(mos) as pétalas ao anoitecer. Esse trecho parece-nos paradigmático por duas razões: por apresentar os dois elementos (premissa e conseqüência/ilustração) — servindo para sintetizar em termos estéticos uma visão cósmica globalizadora presente também em outros setores da vida filosófica e cultural da época - e por ser de autoria de um dos últimos poetas de expressão latina, que, vivendo numa época que levaria ao desabrochar definitivo das línguas vulgares, lança nesse poema uma das sementes temáticas que será explorada à exaustão nos séculos seguintes.

A concepção aí expressa é alegórica: expõe um pensamento de forma figurada, representando uma coisa para dar idéia de outra (conceito clássico de alegoria). Trata-se de uma concepção alegórica da natureza que se expressa de forma artística. A concepção alegórica da natureza, seria, segundo os estudiosos, o modo por excelência como o homem medieval vivia no mundo: mundo povoado de significados, em que tudo era "signo" de algo, em que os sentidos eram sempre supra-sentidos, manifestações de Deus ou de um poder superior nas coisas. "A natureza falava uma linguagem "heráldica": um leão era muito mais que um leão, e um hipogrifo era real como um leão porque, como este, era signo, irrelevante existencialmente (grifo nosso), de uma verdade superior" (Eco, 1987, p. 68).

Às manifestações da concepção alegórica da natureza e da concepção alegórica em arte Hansen dá as denominações, respectivamente, de alegoria dos teólogos e alegoria dos poetas, o que na verdade corresponde à classificação medieval entre, respectivamente, allegoria in factis e allegoria in verbis. Enquanto a alegoria dos poetas seria "construtiva ou retórica, a dos teólogos seria interpretativa ou hermenêutica". Aquela é uma alegoria de palavras; esta, uma alegoria factual. Segundo ele, as duas são complementares: como expressão, "a alegoria dos poetas é uma maneira de falar; como interpretação, a alegoria dos teólogos é um modo de entender" (1987, p. 1). Ainda citando Hansen: "O básico a ser mantido dessas distinções é que a alegoria factual afirma uma similitude essencial, desejada e escrita por Deus, ao passo que a alegoria verbal é produto apenas da imaginação humana, como ficção" (1987, p. 55). Iniciamos este artigo ressaltando essa distinção porque grande parte dos estudos da alegoria na Idade Média leva em conta apenas aquilo que Hansen chama de "alegoria dos teólogos/hermenêutica/factual". Por serem ambas "complementares", no estudo da alegoria dos poetas não é possível ignorar de todo a alegoria hermenêutica, e não nos parece demais ressaltar essa complementaridade. Como vemos, ambas estão presentes no

\footnotetext{
${ }^{2}$ As traduções de todos os trechos extraídos de edições estrangeiras são da autora deste trabalho.
} 
poema que nos serviu de epígrafe: sobre a base de uma visão alegórica da natureza, o poeta constrói uma alegoria estética. Essa coexistência não é obrigatória em tese, como se verá, mas na Idade Média é uma constante.

Só para fins de clareza, é preciso delimitar as duas atitudes e optar pelo aprofundamento naquela que for objeto de estudo. Aqui nos deteremos na alegoria dos poetas. Para um estudo mais aprofundado de ambas e de seus matizes, remetemos à obra de Hansen.

A origem da atitude alegórica medieval não se confina à Idade Média, e nisso há unanimidade. Em Curtius e em Eco encontram-se os dados históricos mais claros. Este último nos diz, por exemplo, que na origem do alegorismo medieval estão as cosmologias pitagóricas. Uma delas "retoma e unifica os temas tradicionais da teoria do homo quadratus. Sua origem foram as doutrinas de Calcídio e Macróbio, especialmente este último (Somnium scipionis II, 5), que lembrava que physici mundum magnum hominem et hominem brevem mundum esse dixerunt. O cosmo como grande homem e o homem como pequeno cosmo. É esse o ponto de partida de grande parte do alegorismo medieval em sua tentativa de interpretar, através de arquétipos matemáticos, a relação entre microcosmo e macrocosmo. $\mathrm{Na}$ teoria do homo quadratus o número, princípio do universo, assume significados simbólicos, fundado em séries de correspondências numéricas que são também correspondências estéticas" (1987, p. 47). Como se vê, reencontramos aqui Calcídio e Macróbio, os mesmos nomes que costumam ser associados a Alain de Lille.

Assim, seria preciso ver na atitude alegórica medieval "uma disposição para prolongar a atividade mitopoética do homem clássico, elaborando novas figuras de referências em harmonia com o ethos cristão" (Eco, 1987, p. 68). Não pudemos deixar de observar, em toda a leitura de Eco, que subjacente à sua interpretação está aquilo que Hansen considera a configuração "hermenêutica" da alegoria. Para Eco, esta (que ele chama de concepção alegórica da natureza) constituiria o húmus em que se desenvolveu a outra. Com o que concordamos plenamente. No entanto, os estudiosos nem sempre estabelecem uma ponte entre a feição cristã da alegoria e sua outra face, puramente laica e literária, presente na tradição da poesia cortês francesa derivada do Roman de la rose, que estaria na esteira da tradição iniciada por Alain de Lille, que nos serviu de epígrafe. O mesmo comportamento observamos em Lukács (1970).

Buscando as fontes antigas da alegoria, todos se referem à Grécia, mais especificamente a Homero. Segundo os estudiosos, nos poetas pré-homéricos a sabedoria estaria ainda envolta em enigmas, mas um dia,

\footnotetext{
finalmente, entre os gregos, a sabedoria começou a humanizar-se e quis comunicar-se a muitos. Lançou fora o manto sob o qual era difícil reconhecê-la, permanecendo, porém, vestida, sem disfarce, de modo que era reconhecivel pelos que a buscavam e contemplavam; sob essa forma, revela-se na obra de poetas conhecidos. Seu grande mestre foi Homero [...]. A Ilíada chegou a ser um compêndio para uso de reis e regentes, e a Odisséia outro tanto para a vida doméstica; a ira de Aquiles e as aventuras de Ulisses são apenas a tessitura do véu. Homero transformou em imagens sensiveis as especulações filosóficas sobre as paixões humanas, dando assim simultaneamente a seus conceitos um corpo, animado por encantadoras imagens" (Winckelmann, Versuch einer Allegori [1766], ed. Dressel, 1866, apud Curtius, 1996, p. 266.).
} 
Portanto, Homero foi "didático" e, por meio de suas imagens, tornou exotérico aquilo que antes era puramente esotérico.

Também em Curtius encontra-se a noção de que o alegorismo de Homero foi adotado depois pela historiografia e pelas ciências naturais. Corresponde a uma característica essencial do pensamento religioso grego: a crença de que os deuses se comunicavam de forma enigmática, por meio de oráculos e mistérios. Incumbia ao homem iniciado penetrar nesses véus e invólucros que escondiam aos olhos humanos o segredo - uma idéia que ainda aparece em Agostinho. Esse é o elo a unir a postura alegórica antiga à medieval, confirmando as palavras de Eco, de harmonização da atitude mitopoética antiga ao ethos cristão.

Mas é também num poeta da Antiguidade que Hansen vai buscar uma expressão da alegoria dos poetas (que ele igualmente chama de alegoria retórica). Seu exemplo é Horácio (Ode XIV — À República (Ad Republicam), em tradução livre (ao que parece do próprio Hansen):

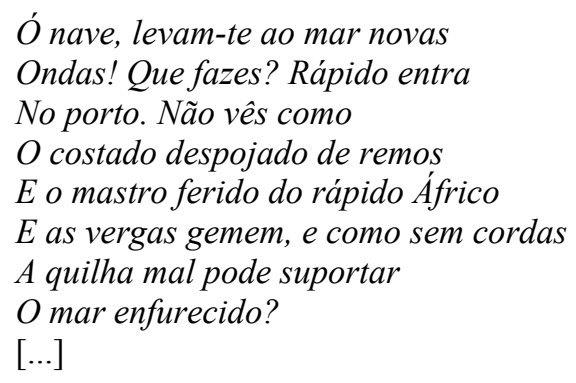

Citamos apenas os primeiros períodos porque eles nos parecem suficientes para ilustrar o assunto. Após a apresentação da Ode, Hansen comenta que, "ao que parece, Horácio compôs a ode depois da Batalha de Filipes (42 a.C.). O navio alegoriza Roma, o mastro destruído designa Pompeu, assassinado no Egito por ordens de Ptolomeu. Nessa linha, "Africus ventus" - "o vento Áfrico" — tem o significado alegórico ou figurado, /vento/, encobrindo outro, próprio, /rei egípcio/".

Enfeixando Homero, Horácio, o ethos cristão e a alegoria medieval, a definição de Lausberg:

A alegoria é a metáfora continuada como tropo do pensamento e consiste na substituição do pensamento em causa por outro pensamento, que está ligado, numa relação de semelhança, a esse mesmo pensamento (1967, § 423).

Então, a nave é a república, o vento Áfrico é o rei egípcio etc.

No entanto, a alegoria de Allain de Lille não é a alegoria de Horácio. Que não é a do Roman de la rose. Trataremos disso adiante.

$$
* * *
$$

Voltando, pois, à evolução do alegorismo a partir da Antiguidade, é pertinente lembrar a trajetória que leva de Homero ao Roman de la Rose. Quem a descreve é Curtius (1996, p. 265):

Os gregos não quiseram renunciar nem a Homero nem à ciência. Buscaram um equilíbrio e encontraram-no na interpretação alegórica de Homero que segue de muito perto a crítica homérica dos pré-socráticos. Começada no século VI, desenvolve diferentes tendências e fases, 


\begin{abstract}
em que não iremos insistir agora. No fim da Antiguidade a alegoria adquire novo poder sobre os espíritos, e o judeu helenizado Fílon aplica-a ao Antigo Testamento. Desse alegorismo bíblico judaico procede o alegorismo cristão dos Padres da igreja. O paganismo agonizante estendeu também a Virgílio a explicação alegórica (Macróbio). O alegorismo bíblico e virgiliano confluem na Idade Média; dai a alegoria tornar-se, geralmente, a base de qualquer interpretação de texto. Aqui está a raiz de tudo o que se pode denominar alegorismo medieval. Expressa-se também na 'moralização' de Ovídio e de outros autores, através da explicação alegórica; assim como no fato de que os seres personificados da natureza supra-sensivel -o homem do fim da Antiguidade, como já vimos, inclinava-se a isso (grifo nosso) - podiam tornarse atores de criações poéticas: da Psichomachia de Prudêncio à ética filosófica do século XII; desta ao Romance da Rosa, a Chaucer, a Spencer, aos autos sacramentales de Calderón. A concep̧̧ão alegórica de Homero ainda era admitida sem discussão por Erasmo (Enchiridion, c. 7).
\end{abstract}

Assim, Curtius, com seu saber enciclopédico, traça em rápidas pinceladas o caminho que leva da alegoria antiga à medieval e, tomando atalhos, passa de raspão pelo Roman de la Rose, sem dizer (talvez deixando implícito) que ele é um dos grandes pontos de convergência desse dédalo. Apesar de tudo, sentimos falta, nessa enumeração, de um ingrediente importante para o nosso caso: as imagens colhidas no paganismo popular (veremos isso melhor adiante).

Mas, continuando com Curtius, é nele também que encontramos uma descrição sucinta da tradição herdada do Roman de la rose (1996, pp. 173-175). Ele o qualifica, em sua primeira parte (de autoria de Guillaume de Lorris), como uma alegoria do amor:

O jovem poeta sonha que em plena primavera chega a um jardim murado. Ali reina Amor, assistido por Alegria, Juventude e Generosidade. O jovem avista uma rosa, que desejaria colher. Cerca-a, porém, uma sebe de espinhos, vigiada por Medo, Vergonha, Difamação e potências afins: todas as personagens alegóricas barram-lhe o acesso. Aqui se interrompe subitamente a primeira parte, que devia coroar-se com a conquista da rosa. Cerca de quarenta anos mais tarde, o tradutor e poeta Jean de Meun continua a obra, concluindo-a com dezoito mil versos. Ele acolhe a fábula e as personagens (grifo nosso) [...] O Romance da Rosa contava, ainda no século XVI, numerosos leitores, assim como a obra de Alain, novamente divulgada (grifo nosso) (Curtius, pp. 173-175).

Essa tradição, que vem à tona no século XIII, não só fornece alimento para grande parte da produção poética cortês na França medieval como também inspira e ornamenta os acontecimentos da vida real na corte durante o período. Seu apogeu poético, diríamos, está em Charles d'Orléans, a partir do qual começa a perder o viço e a pujança. Mas, como dizia Curtius, citado acima, o Roman de la rose ainda no século XVI tinha numerosos leitores, e não podemos deixar de sentir suas ressonâncias na famosa "Carte du Tendre" de Mlle. de Scudéry, em pleno século XVII, mesmo após a verdadeira revolução que foi o Renascimento. Trata-se de um mapa que, se não repete ipsis litteris as denominações presentes em nosso poeta e no Roman de la rose, reproduz, em nomes de acidentes geográficos, uma mesma atitude estética que se mostra capaz de resistir a séculos de evolução artística.

Aqui cabe tecer algumas considerações sobre os reflexos do alegorismo na vida social da corte francesa no período que abrange a produção poética de Charles d'Orléans, antes de passarmos ao estudo mais pormenorizado do uso que esse poeta faz das figuras alegóricas. 
Quem traça um panorama bastante abrangente dos reflexos da atitude alegorizante na vida social e estética da corte francesa nesse período é Huizinga (1999). Suas observações freqüentam com assiduidade as páginas de estudos medievais: seja para acatá-las, comentálas ou refutá-las, raros são os que as ignoram. Passaremos à análise de algumas delas, pois nos parecem extremamente esclarecedoras para o nosso estudo. Diz ele:

A Idade Média nunca esqueceu que todas as coisas seriam absurdas caso o sentido delas fosse esgotado na função que desempenham e no lugar que ocupam no mundo fenomênico, caso, por sua essência, elas não atingissem um mundo situado além deste. [...] Esse é, então, o fundamento psicológico da origem do simbolismo ${ }^{3}$. [...] Na Idade Média a atitude simbolista era muito mais evidente do que a atitude causal ou a genética [...]. Do ponto de vista causal, o simbolismo aparece como uma espécie de curto-circuito do pensamento. Em vez de procurar a relação entre duas coisas seguindo os caminhos ocultos de seus nexos causais, o pensamento dá um salto e descobre sua relação não no nexo de causa ou de efeito, mas no nexo de significação ou finalidade (1999, p. 183-184). ${ }^{4}$

Continuando em sua análise de feição psicológico-cognitivista, Huizinga considera que, do ponto de vista da psicologia experimental, todas as associações mentais baseadas em similitudes e causas quaisquer imediatamente despertam a idéia de um nexo essencial e místico. Mas:

O simbolismo perderá essa aparência de arbitrariedade se levarmos em conta o fato de que ele está indissoluvelmente ligado com a concepção de mundo que foi chamado de realismo na Idade Média e que a filosofia moderna prefere chamar de idealismo platônico, embora de modo menos correto. A assimilação simbólica baseada em propriedades comuns pressupõe a idéia de que essas propriedades são essenciais às coisas [...]. Produz-se assimilação porque os atributos são os mesmos: beleza, ternura, pureza, cores das rosas, tudo isso é comum às virgens, e a cor vermelha é a cor do sangue dos mártires. Mas a similaridade só terá significado místico se o termo médio que interliga os dois termos do conceito simbólico expressar uma essencialidade comum a ambos; em outras palavras, se a vermelhidão e a brancura forem algo mais do que nomes de uma diferença física baseada em quantidade, se forem concebidos como essências, como realidades (grifo nosso) (1999, p. 185).

Diríamos que, no caso de Alain de Lille, esse terceiro elemento seria constituído pela semelhança do desenvolvimento vital da rosa com a do ser humano. Mas também é preciso acrescentar que, para chegar a estabelecer essa semelhança, o poeta partiu da premissa do reflexo entre duas realidades: uma transcendente e outra imanente.

Adiante, Huizinga diz:

A mentalidade do selvagem ${ }^{5}$, da criança e do poeta nunca vê as coisas de outra maneira. Então, uma vez que beleza, ternura e brancura são realidades, também são entidades; conseqüentemente, tudo o que for belo, terno ou branco deverá ter uma essência comum, a mesma razão de existência, o mesmo significado diante de Deus (1999, p. 185).

\footnotetext{
${ }^{3}$ Note-se que Huizinga não cita a distinção feita por Goethe entre alegoria e simbolismo (V. adiante), embora não pareça ignorá-la. À guisa de parênteses, vale notar que Eco reconstituiu em bases filosóficas (ver acima: relação microscosmo/macrocosmo) aquilo que Huizinga explica com afirmações de cunho psicologizante.

${ }^{4}$ Comparar esses conceitos de Huizinga com o que dizemos abaixo sobre a relação de reflexo entre elementos de duas isotopias diferentes.

${ }^{5}$ Deixamos de transcrever aqui nossas considerações sobre a concepção de "mentalidade primitiva", bastante controversa, por uma questão de espaço.
} 
Isso indicaria as fortes ligações existentes entre o simbolismo e o realismo no sentido escolástico. ${ }^{6}$ E também:

Tudo o que era pensável havia adquirido forma de imagem: a concepção tornara-se quase inteiramente dependente da imaginação. Ora, um idealismo extremamente sistemático (era isso o que significava realismo na Idade Média) confere certa rigidez à concepção do mundo. Sendo concebidas como entidades que só tinham importância em virtude de sua relação com o Absoluto, as idéias organizam-se facilmente como estrelas fixas no firmamento do pensamento. Uma vez definidas, elas se prestam apenas à classificação, à subdivisão e à distinção de acordo com normas puramente dedutivas (1999, p. 195).

Aqui cabe notar que, embora use os termos simbolismo e alegoria de maneira intercambiável, Huizinga parece acatar implicitamente a distinção que Goethe faz entre ambos, mesmo não fazendo referência explícita a elas. De modo sucinto, essa distinção seria a seguinte:

“- A alegoria transforma o fenômeno em conceito, e o conceito em imagem, mas de tal modo que o conceito na imagem seja considerado sempre circunscrito e completo na imagem e dado a expressar-se através dela.

- O simbolismo transforma o fenômeno em idéia, a idéia em imagem, de tal modo que a idéia na imagem permaneça sempre infinitamente eficaz e inacessível, e, ainda que pronunciada em todas as línguas, continue inexprimível.

- É muito diferente o poeta procurar o particular em função do universal ou ver no particular o universal. No primeiro caso tem-se a alegoria, na qual o particular vale só como exemplo, como emblema do universal; no segundo caso, revela-se a verdadeira natureza da poesia: exprime-se o caso particular sem pensar no universal e sem aludir a ele. Quem capta esse particular vivo capta, ao mesmo tempo, o universal sem ter consciência disto, ou só tomando tal consciência mais tarde.

- O verdadeiro simbolismo é aquele no qual um elemento particular representa o elemento mais geral, não como sonho ou sombra, mas como revelação viva e instantânea do imperscrutável." (Goethe, Maximen und reflectionen, Werke, Leipzig, 1926, apud Eco,1987, pp. 72-73)

Esquematizando o texto acima para melhor compreensão:

ALEGORIA $=$ fenômeno $\rightarrow$ conceito $\rightarrow$ imagem

- conceito: circunscrito e completo na imagem; exprime-se através dela;

- o particular em função do universal (o particular vale como exemplo, como emblema do universal);

SÍMBOLO $=$ fenômeno $\rightarrow$ idéia $\rightarrow$ imagem

\footnotetext{
${ }^{6}$ O termo "realismo", segundo Abbagnano (1998, v. Realismo) "começou a ser usado mais ou menos no fim do séc. XV para indicar a corrente mais antiga da Escolástica, em oposição à corrente "moderna" dos nominalistas ou terministas. O realismo afirmava a realidade (grifo nosso) dos universais (gêneros e espécies), entendendo, porém, de modos diferentes a própria realidade." Segundo Thomas Ransom Giles, para o chamado realismo platônico, "as Formas Universais, as Idéias, as Essências existem no mundo eterno, ou seja, no mundo ideal, totalmente independentes de quem as percebe [...] como únicas verdadeiras realidades que existem." (1993, v. Realismo).
} 
- a idéia na imagem permanece infinitamente eficaz e inacessível;

— no particular vê o universal (particular não alude ao universal, mas quem capta esse particular capta também o universal).

Portanto, os pontos básicos utilizados pela distinção de Goethe são, de um lado, conceito vs. idéia e, de outro, particular vs. universal.

E aqui recorremos a Lukács (1970, p. 1475) para entender ao que Goethe estava aludindo quando falava em "idéia":

Se, na simbólica, a idéia figura como princípio da mediação entre fenômeno e imagem, cabe examinar com atenção a diferença entre conceito e idéia na filosofia clássica alemã. Já em Kant idéia pretende ser síntese de uma totalidade; em relação ao conceito, tende à integridade e ao movimento dialético, à elasticidade [...]. Na Crítica do juízo, que Goethe estudou a fundo, Kant define a idéia estética como uma 'representação da imaginação' à qual nenhum conceito determinado pode ser adequado e que, portanto, 'nenhuma língua pode perfeitamente exprimir e tornar compreensivel'.

Já para Kant, conceito é algo limitado à realidade fenomênica (única acessível ao homem).

São 'formas do intelecto', 'condições dos objetos fenomênicos'. Entram na constituição dos próprios objetos fenomênicos, ou seja, objetos de toda experiência possível. (Crítica da razão pura, Analítica dos conceitos, par. 10, apud Abbagnano, 1998, p. 183, v. Concetto).

Portanto, na base da distinção estabelecida por Goethe encontram-se definições kantianas postas a serviço do "símbolo", construto privilegiado em detrimento da "alegoria". Essa postura é dissecada por Hansen nos seguintes termos:

No romantismo o símbolo passa a ser violentamente oposto à alegoria. Confundida numa só - a alegoria - é então conceituada como particular para o universal (Schelling, Goethe), como invólucro ou revestimento exterior de uma abstração. Segundo os românticos, o símboloque a tradição antiga, greco-latina, medieval e renascentista não distinguia da alegoria - é uma espécie de paradigma ou classe da qual ele é o único elemento. Por isso, sua significação é sempre imediata: em sua particularidade, ele contém ou expressa o geral [...]. As noções românticas da arte como expressão incondicionada do artista gênio em contato fulminante com potências cósmicas levaram a descartar a alegoria pelo seu caráter evidente de convenção retórica” (Hansen, 1987, pp. 5-6).

A distinção goethiana de fato contém um viés depreciativo em relação à atitude alegorizante. Coisa que Lukács valida ${ }^{7}$ e que mal se esconde em Huizinga, quando ele qualifica de peculiar aos "primitivos" essa mesma atitude.

Um resultado prático da atividade simbólico-alegórica estética na Idade Média, em particular no período e na região que nos interessa, foi a construção de todo um sistema estético que funcionava por um mecanismo de auto-alimentação e realimentação. A harmonia de idéias criada por tal atividade acabou configurando uma base para a confirmação da validade das tradições subjacentes e para a sua perpetuação. Adiante veremos com mais vagar a importância da tradição no período.

\footnotetext{
${ }^{7}$ Aliás, é de se ressaltar que Lukács desenvolve todo o seu raciocínio em torno daquilo que Hansen chama de alegoria factual/hermenêutica ou "dos teólogos".
} 
De qualquer modo, está claro que o hábito de expressar-se por mitos, herdado da Antiguidade ou não, assumiu na alegoria dos poetas desse período da Idade Média francesa configurações peculiares. Dentre essas peculiaridades, o componente pagão é bem perceptível. Pode-se dizer então que, nesse período, a junção entre, de um lado, expressão mitológica e alegórica antiga, e, de outro, heranças pagãs dos antigos povos bárbaros, gerou a alegoria medieval sob o rolo compressor da Igreja Católica. Um belo exemplo dessa síntese está na lenda de Melusina ${ }^{8}$. Criou-se, nesse cadinho, um sistema interpretativo-cognitivo de que o homem medieval se serviu por muito tempo, alimentando com ele todo um riquíssimo arcabouço metafórico.

Huizinga afirma que o "simbolismo [aqui (con)fundido com a alegoria] era como um segundo espelho alimentado pelo espelho do próprio mundo fenomênico" (1999, p. 194). É assim que Huizinga expressa aquilo que acima chamamos de "realimentação"; no seu caso, ideo(-)lógica. Diz ele também que, "quando o homem medieval quer conhecer a natureza e a razão de alguma coisa, nunca olha dentro dela, para analisar sua estrutura, nem atrás dela, para buscar sua origem, mas olha para cima, para o céu, onde ela brilha como idéia" (1999, p. 195). Hábito herdado, como vimos, do pitagorismo através do "realismo" medieval, também conhecido como "idealismo platônico". O resultado prático de "olhar-se para cima" em busca da "idéia" como "princípio universal", em termos do fazer poético da época e da região que estudamos, foi a criação de uma verdadeira convenção terminológica

\footnotetext{
${ }^{8}$ Romance de Melusina ou história dos Lusignan, Jean d'Arras, ed., Martins Fontes, S.Paulo, 1999. Em seu posfácio, de Michèle Perret, lê-se: "Estamos em plena guerra dos Cem Anos, em terras de Poitou [...], e foi na batalha de Poitiers que João, o Bom, perdeu a liberdade e boa parte de seu reino. Depois, com Bertram du Gueslin, começou a reconquista, e então a terra de Poitou foi dividida, passando a ser os "fortes e castelos, entrelaçados uns nos outros, uns ingleses, outros franceses", como diz o cronista Froissart. Nessa região [...] situa-se uma fortaleza, Lusignan. [...] Agora, durante a guerra dos Cem Anos, há quase vinte anos está em poder de João de Berry. [...] Creswell [que tomara conta dela para os ingleses, antes da reconquista], provavelmente durante o cativeiro, "com todos os juramentos que um homem de bem pode fazer", disse que, algum tempo antes da rendição da praça-forte, viu certa noite, em seu quarto cuidadosamente fechado, a aparição em plena luz de uma serpente grande e grossa, com cauda listrada de azul e prata. A serpente bateu a cauda no leito, depois se transformou em mulher alta e bela, magra e esbelta, vestida à moda antiga. [...] Sua presença anunciava que era preciso resignar-se a perder a praça-forte. [...] É verdade que a boa fortaleza fora berço de uma família que tinha um destino pouco comum. [...] É então, nesse oeste da França desmantelado pela guerra, que surge de repente, nos dois partidos, a vontade de "romancear" a história da fundação da fortaleza de Lusignan e da linhagem de que ela fora berço! Em 1392, João de Berry incumbiu certo Jean d'Arras [...] de "pôr em prosa" a história da fada de Poitier, fundadora da linhagem dos Lusignan, e para isso lhe deu toda a documentação necessária, velhas crônicas e testemunhos recentes. [...] A razão desse interesse súbito pela história legendária de uma família extinta, por parte desses senhores efêmeros de uma terra que não conseguem conservar, deve ser buscada na necessidade de ancorar-se no mais profundo passado cultural da província. É fácil imaginar esses incertos senhores atentos aos relatos de velhas lendas, procurando os documentos antigos sobre o passado das terras conquistadas, para apropriar-se do essencial de um território que lhes escapa das mãos. Mas que lendas, que passado? $\mathrm{Na}$ qualidade de fada, a dama pertence a um mundo pré-cristão, é divindade gaulesa das águas e das fontes, talvez também da fecundidade e da morte, que surge das florestas e da noite. Na qualidade de serpente, vem de um passado mais arcaico ainda, de mitos indoeuropeus, pertencendo à simbólica universal da serpente. De qualquer modo, ela não é a única fada da Idade Média a seduzir um mortal: o tema do cavaleiro que vai viver no "outro mundo", de uma mulher conhecida numa fonte, é comum na literatura medieval. Às vezes a fada é construtora, como Brunhilda, a avó de Oberon; outras vezes a sedutora é serpente, como a "guivre" ou "vuivre" do Bel Inconnu de Renaut de Beaujeu, quase um século antes do ingresso de Melusina na literatura."
} 
estruturadora, com tudo o que isso pressupõe de contradição com a própria concepção inicial platonizante: em última análise, seria possível dizer que, por caminhos tortuosos, partiu-se do realismo platônico e chegou-se à convenção, a uma espécie de nominalismo prático ${ }^{9}$. É assim que a mentalidade idealista — que na Idade Média recebe o nome de realismo - acaba por gerar conseqüências materializantes, uma espécie de idealismo mágico em que o abstrato se transforma em concreto. Essa concretização do abstrato é configurado por uma das variantes da realização da alegoria, a personificação ou prosopopéia. Em Charles d'Orléans, mais talvez do que em todos os poetas da época, a tentativa de expressar sentimentos, emoções, pensamentos por meio de Idéias de sentimentos, de emoções e de pensamentos ocasionou uma exacerbação do recurso à personificação, figura na qual "o orador ou escritor empresta sentimentos humanos e palavras a seres inanimados, a animais, a mortos ou a ausentes" (segundo definição do dic. Houaiss), porém, mais que isso, figura na qual o abstrato acaba por ser animado, concretizado, antropomorfizado, coisificado para se fazer ver, tocar, ouvir, entender. Figura na qual o abstrato deixa de ser idéia e vira nome. Ganha corpo. Mas da personificação trataremos com mais detalhes depois.

Em resumo, os fatores acima, conjugados, deram origem a um sistema "mitológico" terminologicamente estruturado que, na França, ganhou forma e carne no Roman de la Rose e acabou constituindo uma espécie de ligante para alguns estratos sociais que buscavam em algum tipo de sistema uma base para a convivência com a (ou na) realidade. O sistema assim criado, por sua vez, tinha uma coerência interna suficiente para realimentar-se e, portanto, perpetuar-se. A força das personificações encontradas em Charles d'Orléans, herança direta das personificações do Roman de la Rose, só se justifica pelo fato de constituírem todo um arcabouço estruturado de comunicação e expressão de sentimentos e pensamentos, cuja durabilidade só pode ser explicada pela real utilidade que teriam. O Roman de la rose constituiu aquilo a que Barthes dá o nome de ideoleto, verdadeiro linguajar de uma ideologia (2003, p. 178). ${ }^{10}$

Tal situação não se restringia à produção estética: abrangia também a vida social, permeava as cerimônias, os rituais, os divertimentos. Na "corte do amor" que Luís de Bourbon solicitara ao rei, para proporcionar alguma distração durante uma epidemia que avassalava Paris, tinha-se um salão literário em que era cultuada a causa da cavalaria com os nomes da cortesia. Dela participavam, entre outros, João Sem Medo, seu irmão Antoine, seu filho de seis anos, Felipe ${ }^{11}$. As personificações do Roman de la Rose expressavam os matizes

\footnotetext{
${ }^{9}$ Os nominalistas escolásticos negavam a existência dos universais no sentido platônico. Para entender sua posição talvez seja interessante atentar para as palavras de Leibniz: "são nominalistas todos os que acreditam que, além das substâncias singulares, só existem nomes puros, eliminando, portanto, a realidade das coisas abstratas e universais" (De stilo philosophico Nizolii, 1670, Op., ed. Erdmann, p. 69, apud Abbagnano, 1998, v. Nominalismo).

${ }^{10}$ De acordo com Barthes, a duração (durée) de uma ideosfera (círculo, sistema de idéias-frases, de idéias fraseadas, de argumentos-fórmulas, de fórmulas, portanto um objeto de linguagem essencialmente copiável e/ou repetível - 2003, p. 188) não é demonstração de sua validade, mas sim de sua resistência (endurance) (2003, p. 189); completaríamos dizendo, portanto, que pode ser reflexo de sua utilidade.

11 Segundo descrição de Huizinga, "a corte foi fundada com base nas virtudes da humildade e da fidelidade [...]. Seus membros receberam títulos ilustres. Os dois fundadores e o rei foram chamados de Grandes Conservadores. Entre os conservadores estavam João Sem Medo, seu irmão Antoine, seu filho de seis anos,
} 
dos sentimentos, constituindo-se em termos de um verdadeiro saber psicológico. $\mathrm{O}$ conhecimento desses fatos é indispensável para entender o grande uso de personificações por parte dos poetas da época e do período. Em Charles d'Orléans, elas estão presentes tanto quanto em seus predecessores, mas de forma exacerbada, exuberante e - o que é importante — em tensão.

No entanto, como já assinalamos acima, a alegoria do Roman de la rose não é a mesma que Hansen distingue em Horácio, assim como não é a mesma encontrada em Alain de Lille.

Se reexaminarmos os exemplos dados acima, lançando mão da terminologia desenvolvida por Dubois et al. (1977), a partir de Greimas, poderemos dizer que a diferença entre ambos está na relação entre as isotopias em jogo. No caso de Alain de Lille, temos duas grandes isotopias: transcendente (macrocosmo) e imanente (microcosmo). Entre as duas há, implicitamente, uma relação hierárquica: o grande reflete-se no pequeno, que é sua manifestação. Somente graças a esse tipo de relação é que qualquer ação atribuída a um dos elementos da isotopia pode ser deslocada automaticamente para o outro. Tais conceitos não podem ser entendidos sem a consideração de suas implicações filosóficas (platônico-cristãs) subjacentes. Para o elaborador de tais vínculos isotópicos, a relação existente entre os dois elementos das isotopias é de ordem transcendente; portanto, não é aleatória, não é fruto da vontade de um inventor estético (o poeta); é fruto da vontade de um criador cósmico. Reflexo é a palavra-chave. Trata-se, portanto, essencialmente da alegoria hermenêutica (segundo terminologia de Hansen) usada esteticamente.

Em Horácio, a relação entre as isotopias é de substituição de signos segundo uma lógica de topoi. No caso, as isotopias náuticas e políticas se entrecruzam graças a topoi reconhecíveis: o uso de certos significantes pertencentes à isotopia náutica é capaz de remeter a significados políticos graças a convenções reconhecidas por certa comunidade. Embora neste caso se possa falar em aleatoriedade de relações (estabelecidas por um inventor estético que se apresenta como tal), esta é relativa por precisar obedecer a certas convenções para que a metáfora seja reconhecida. Ainda assim é maior que no primeiro caso, pois naquele o contato entre dois termos se baseia na crença numa afinidade essencial entre eles, logo numa crença comungada por uma comunidade (filosófica, religiosa, política etc.) e nem sempre dependente apenas da inventividade de um indivíduo. Intercâmbio de signos é a expressão-chave, e essa figura é típica da alegoria dos poetas, segundo terminologia de Hansen.

A alegoria de Charles d'Orléans é ainda diferente dessas duas. Tem outro caráter, o caráter da prosopopéia. Embora os autores costumem identificar personificação e prosopopéia, mostraremos aqui uma distinção de uso que será útil para caracterizar a obra de Charles d'Orléans. Se compararmos:

Felipe. Certo Pierre d'Hauteville, de Hainault, era príncipe do amor; havia também dois ministros, auditores, cavaleiros da honra, cavaleiros tesoureiros, conselheiros, grão-mestres da caça, escudeiros do amor etc. Ao lado de príncipes e prelados foram admitidos burgueses e representantes do baixo clero". Apresentavam-se refrões que deviam ser transformados em baladas, canções, rondéis etc. Havia debates. As damas distribuíam os prêmios, e eram proibidos poemas que atacassem a honra da mulher (1999, p. 103). 
Ó nave, levam-te ao mar novas

Ondas! Que fazes? Rápido entra

No porto. Não vês como

O costado despojado de remos

E o mastro ferido do rápido Áfrico

com:

Mort de moy! vous y jouez vous

Avec Dame Merencolye!

Mon cueur, vous faictes grant folye!

C'est la nourice de Courroux.

traduzido:

Irra! Essa é tua diversão?

Brincares com Melancolia!

Meu coração, tu tresvarias!

Tal dama é ama da Aflição.

veremos que, no primeiro caso, os objetos inanimados ganham vida e, ao mesmo tempo, representam coisas diferentes daquelas que seus nomes denotam: nave não é embarcação, é a república; Áfrico não é vento, é o rei egípcio. Temos então uma metáfora em que um elemento está por outro num tipo de relação de substituição. Entretanto, no exemplo de Charles d'Orléans Coração é coração (na sua conotação poética, mas não está por outra coisa); Melancolia é um tipo de sentimento que não está por outra coisa senão por si mesmo etc. Embora não se costumem estabelecer distinções dentro de uma grande categoria alegórica chamada personificação ou prosopopéia, devemos convir que aí se encontram dois processos diferentes de abordagem. Se, no primeiro caso, não se nomeiam as coisas diretamente, mas a elas se faz referência por meio de substantivos comuns, num processo de conceituação por substituição da coisa, no segundo dá-se vida a conceitos, transformando substantivos comuns em substantivos próprios, em verdadeiros agentes. Em suma, o processo é inverso: no primeiro caso transformam-se substantivos próprios em comuns; no segundo, comuns em próprios. Se no primeiro uma pessoa é representada por uma coisa (rei egípcio $\rightarrow$ vento Áfrico), no segundo uma coisa é transformada em pessoa (Melancolia $\rightarrow$ ama). Portanto, mais lógico seria chamar o primeiro processo de reificação e o segundo de personificação. Comum a ambas, o processo de animação, em que o inanimado é animado, no primeiro caso para substituir um ser animado; no segundo, para agir como ser animado, sem substituição. Deste ponto de vista, no primeiro caso há um processo metafórico propriamente dito; no segundo, não. Isto porque:

(a) no primeiro caso há substituição de um termo "próprio" por um "figurado" ou "impróprio", ou seja, o termo substituído e o substituinte pertencem a isotopias diferentes (por exemplo, nave $\rightarrow$ república em sentido "próprio");

(b) no segundo caso não há substituição por termo diferente; o desvio em relação ao grau zero ${ }^{12}$ do termo ocorre por relações sintagmáticas, como veremos abaixo.

\footnotetext{
12 Tomado aqui no sentido de denotação.
} 
Assim, poderíamos dizer que, em termos paradigmáticos, no exemplo acima as palavras Melancolia, Coração e Aflição constituem um tropo que mais merece ser qualificado de sinédoque (que toma o abstrato pelo concreto) do que propriamente de metáfora. No entanto, em Tal dama é ama da Aflição, temos referências paradigmáticas com relação de similaridade imprópria:

(a) a relação de similaridade é estabelecida pelo verbo ser, de ligação;

(b) a dama, que está por Melancolia, é atribuído o caráter de "ama" (= nutriz, mulher que alimenta), numa relação "imprópria",

o que configura uma metáfora, por semelhança trópica de um atributo impróprio de "melancolia".

E aqui vêm bem a calhar as considerações que Ricoeur faz em torno da distinção estabelecida por Benveniste entre semiótica e semântica. Essa distinção não é o que nos interessa diretamente aqui, pois mais importantes para o nosso estudo parecem ser as ilações extraídas por Ricoeur, para fundamentar sua tese, que estabelece limites para o conceito de metáfora como substituição de palavras. Primeiramente, tentaremos delinear brevemente as afirmações de Benveniste transcritas por Ricoeur e depois passaremos às considerações deste em torno delas:

É por meio da consideração das diferenças de nível na arquitetura da linguagem que o grande sanscritista francês introduz a distinção entre as unidades respectivas da língua e do discurso ${ }^{13}$ : de um lado os signos, do outro a frase. A noção de nível não é exterior à análise: está nela incorporada a titulo de operador (Problèmes de linguistique générale, 122); pode-se dizer, então, que uma unidade lingüistica qualquer só é aceita como tal quando é possivel identificá-la numa unidade de grau superior: o fonema na palavra, a palavra na frase. A palavra está assim "numa posição funcional intermediária que decorre de sua dupla natureza. Por um lado, ela se decompõe em unidades fonemáticas que são de nível inferior; por outro, entra, como unidade significante e com outras unidades significantes, numa unidade de nivel superior" (123) (1975, p. 89).

Essa unidade de nível superior é a frase. Ricoeur continua, ainda citando Benveniste:

“Uma frase constitui um todo, que não se reduz à soma de suas partes; o sentido inerente desse todo está repartido pelo conjunto dos constituintes" (ibid.). [...] A progressão, portanto, não é linear de uma unidade à outra; surgem propriedades novas, que derivam da relação específica entre unidades de níveis diferentes; enquanto as unidades do mesmo nível têm entre si relações distribucionais, os elementos de nível diferente têm relações integrativas. A distinção entre essas duas espécies de relação determina a distinção entre forma e sentido [...] (1975, p. 90).

A seguir Ricoeur passa às conseqüências dessas reflexões para a sua teoria da metáfora. Diz ele que:

A conseqüência é considerável para a extensão de uma distinção tão famosa quanto a distinção entre significante e significado; essa análise do signo só reina na ordem semiótica, e não na ordem semântica. Em semiologia, diz Benveniste, o que o signo significa não precisa ser definido. Para que um signo exista, é preciso e suficiente que seja aceito (chapéu existe? Sim. Chaméu existe? Não); a questão do significado só pede uma resposta sim ou não; isso significa ou não? Se o significado não exige definição intrínseca, é definido extrinsecamente pelos outros signos, que o delimitam no interior da

\footnotetext{
${ }^{13}$ Beveniste prefere o termo discours a parole.
} 
língua. "Cada signo tem como peculiaridade o que o distingue de outros signos. Ser distintivo e ser significante são a mesma coisa" (La Forme et le Sens dans le langage, 35). Assim circunscrita, a ordem do signo deixa para fora a ordem do discurso. (1975, pp. 91-92).

E assim se estabelece a distinção entre a ordem semiótica e a ordem semântica. A seguir, Ricoeur passa a enumerar suas conclusões. A mais importante para o nosso caso é a $6^{\mathrm{a}} .:$ a distinção entre semiótico e semântico acarreta uma nova divisão entre paradigmático e sintagmático:

As relações paradigmáticas (principalmente as flexões, as derivações etc.) dizem respeito aos signos no sistema; são, portanto, de ordem semiótica; para elas, vale a lei do binarismo tão prezada por Jakobson e pelos estruturalistas. Em compensação, o sintagma é o nome da forma específica na qual se realiza o sentido da frase. [...]: se o paradigma é semiótico e o sintagma é semântico, então a substituição, lei paradigmática, deve ser posta do lado do semiótico. Será preciso, portanto, dizer que a metáfora, tratada como discurso - enunciado metafórico -, é uma espécie de sintagma, e não poderemos situar o processo metafórico do lado paradigmático, e o processo metonímico do lado sintagmático. Isso não vedará [...] classificar a metáfora, tomada como efeito de sentido que afeta as palavras, entre as substituições; mas, em contrapartida, essa classificação semiótica não é excludente de uma pesquisa propriamente semântica incidente sobre a forma de discurso, portanto de sintagma, realizado pela metáfora. De fato, é como sintagma que o enunciado metafórico deverá ser considerado, a ser verdade que o efeito de sentido resulta de certa ação que as palavras exercem umas sobre as outras na frase. [...] "É em conseqüência de sua coaptação que as palavras adquirem valores que não possuíam por si mesmas e que são até contraditórios com os que elas possuíam em outro lugar" (Benveniste, La forme et le sens, 38) (1975, p. 100).

Em tais reflexões de Ricoeur, portanto, encontramos eco de nossa observação, de que a metáfora existente em Charles d'Orléans se dá com muito mais freqüência em nível sintagmático do que no paradigmático; assim, o "desvio" se dá na relação entre o plano da expressão e o plano do conteúdo. É o que ocorre, por exemplo, quando ele diz Mon cueur, vous faictes grant folye!; ou: Dame Merencolye [...] C'est la nourice de Courroux. Compare-se com Ó nave, levam-te ao mar novas ondas.

Sempre que, no plano do conteúdo, entrarem elementos simbólicos, que remetam a um pré-texto suposto ou a um texto pressuposto, poderemos classificar as imagens como alegóricas. É o que ocorre com o exemplo de Horácio, é o que ocorre no exemplo abaixo:

Mon cuer loyaulment son serf vy,

Mais a tort l'a habandonné,

Veu que j'ay [tant Amour servy.]

traduzido:

Meu coração, em leal serviço,

Viu-se sem causa abandonado,

Havendo eu tanto Amor servido.

temos as palavras coração e Amor empregados como personificações, na forma analisada acima. Entre ambos, estabelece-se uma relação de vassalagem. Uma vez que, tomados em 
seu grau zero, os termos coração e amor não admitem esse tipo de relação, que é pertinente a outro tipo de isotopia, podemos dizer que a relação assim estabelecida é "imprópria", é metafórica. Mas, a par dessa relação sintagmática entre Coração e Amor, está a pressuposição de um (con)texto em que ao Amor, costumeiramente, se atribuem os qualificativos de príncipe, senhor, rei. Tal (con)texto constitui um verdadeiro arcabouço arquetípico alimentador desse tipo de construção. Ele é convencionado e aceito por uma tradição na qual o poeta se insere ${ }^{14}$. Um dos elementos mais proeminentes desse arcabouço é o Roman de la rose; estabelece-se assim uma intertextualidade de suma importância na análise da obra do poeta e do período.

São as características peculiares dessa relação arquetípica e o recurso sistemático a ela que conferem especificidade alegórica a grande parte da obra de Charles d'Orléans e do seu período. Dizemos recurso sistemático porque as personificações:

a) são sempre as mesmas em toda a sua trajetória poética, constituindo verdadeiras personagens de um grande drama;

b) são as mesmas usadas em um verdadeiro sistema herdado do Roman de la rose e aproveitado (se não com a constância de Charles d'Orléans, mas com alguma regularidade) por toda uma "linhagem" de poetas medievais franceses.

Resta estabelecer a diferença entre tais artifícios poéticos e aquilo que vimos em Alain de Lille. Para resumir, diríamos que:

a) em Alain de Lille o termo A (rosa) se reflete no termo B (vida humana), graças a afinidades de características; ambos os termos são explícitos;

b) em Horácio o termo A ocupa o lugar do termo B, reconhecível graças a uma relação tópica identificada; o termo A é explícito, o B não;

c) em Charles d'Orléans o termo A (personificação) funciona como um termo B pressuposto (pessoa humana); só o termo A é explícito.

Talvez seja possível afirmar que a forma (c) constitui uma espécie de congelamento da forma (a): uma vez que entre os vários elementos do cosmos existe afinidade essencial, é possível atribuir a qualquer de seus elementos as especificidades de quaisquer outros e fazêlos agir de acordo com elas, pressupondo e não mais explicitando tais relações.

O que há em comum nos três tipos é a relação em si entre coisa e pessoa, é o processo de animação operado por uma espécie de magismo poético capaz de conferir atributos humanos a coisas inanimadas.

Aqui transcrevemos de forma esquemática o modo como Zumthor (1972, pp. 157158) vê essa relação. Ele faz uma categorização das personificações num estudo que contempla o fenômeno em geral, e não apenas no nosso autor. Segundo Zumthor, é preciso não só levar em conta o fenômeno puro e simples da personificação, mas também o da reificação (a que aludimos acima). Ainda de acordo com esse autor, ambos os recursos (personificação ou reificação) podem ser, ao mesmo tempo simples ou complexos. A simplicidade ou complexidade pode: (a) ter caráter numérico (do amor surgem dezenas de

\footnotetext{
${ }^{14}$ Esse é um dos fatores pelos quais esse tipo de poesia causa estranheza no leitor moderno.
} 
"personagens" no Roman de la Rose); ou (b) dizer respeito ao grau de abstração, caso gire em torno de um ser humano universalizado ou de um objeto, um acontecimento, uma qualidade (Amigo, Coração, Quaresma, Cortesia, Ódio, Perigo).

De outro ponto de vista, seria possível distinguir, na época da maior ampliação do sistema alegórico, quatro variedades de personificações: (a) a mais freqüente, que, de um termo abstrato, constitui o sujeito de ações humanas; (b) outra que, colocando esse termo num contexto ambíguo, leva-o a cumprir uma função que pode ser indistintamente a de um ser humano ou de uma coisa concreta (La marchandise d'Espérance, do rondel 332 de Charles d'Orléans; (c) uma outra que transforma a abstração em coisa (payer ma Joie empruntée, no mesmo rondel); (d) e a quarta, enfim, que, unindo a um termo concreto uma qualificação moral, confere-lhe uma personalidade pelo menos virtual.

E concluindo essa sua categorização do fenômeno, Zumthor diz:

Em todos os casos a alegoria funciona de maneira idêntica: sem transparência própria, como uma glosa integrada no texto, que não existe em nenhum outro plano a não ser este, atual, de sua literalidade. Elas somam um sujeito não metafórico a um predicado pertencente à ordem da metáfora (grifo nosso), numa figuração que comporta ao mesmo tempo características do concreto e do geral. O objeto que ela apreende encontra-se, por isso mesmo, despojado daquilo que ele tem de único e de pessoal. No entanto, ela o subtrai à abstração do inteligível puro. Parte de uma metáfora colocada como littera, provida de um sentido próprio, sensus litteralis, ao qual ela atribui, por um elo patente, graças à personificação, uma sententia. Em outros termos, ela passa da metáfora à realidade: operação exatamente inversa à do simbolismo, que, do sensível, passa a outra coisa ${ }^{15}$. Donde o caráter irracional da alegoria: ela extrai de um fragmento do real um sentido indiscutível; proclama e engendra uma ordem, clara, desprovida de fimbrias angustiantes. Procede de uma espécie de otimismo fundamental: nada está desprovido de sentido, e este pode ser construído. Implica que a estrutura da verdade está fixada, é objetiva, é explicável, e que aquele que a conhece pode ser modificado por ela."

As alegorias inspiradas no Roman de la Rose sofrem modificações no fim da vida do poeta (bem visível nos rondéis e em algumas canções da maturidade). Como se configuram tais modificações? Não são freqüentes os poemas em que elas estejam absolutamente ausentes; tampouco é grande o número de personificações novas. O que muda realmente são as relações sintagmáticas entre elas, ainda que seu caráter paradigmático permaneça. Com isso se pode entender a importância dessa relação sintagmática, pois é sobretudo ela que determina o caráter dos poemas da maturidade.

E, para finalizar, apresentamos nossa tradução do poema posto em epígrafe.

\author{
No bosque da Longa Demora \\ Tantos madeiros desarvoram \\ Os ventos da Sorte Dolente \\ Que não distingo claramente \\ Caminhos e sendas agora.
}

Rendas pagou-me aqui, outrora, A Mocidade, sem penhora.

\footnotetext{
${ }^{15}$ Como se vê, Zumthor incorpora Goethe.
} 
Nada me resta por semente,

No bosque da Longa Demora.

Velhice diz-me e me adolora:

Para ti preço não vigora

Qual o tiveste antigamente;

Que isto baste e te contente.

Foram-se teus dias e horas.

No bosque da Longa Demora. 


\section{REFERÊNCIAS BIBLIOGRÁFICAS}

BARTHES R., (2003) O Neutro, M. Fontes, S. Paulo, trad. Ivone C Benedetti.

CURTIUS, E.R., (1996) Literatura européia e Idade Média latina, EDUSP, São Paulo, trad. Paulo Rónai e Geraldo Gerson de Souza.

DUBOIS, J. et al. (1977) Rhétorique de la poésie, Éditions Complexe/Presses Universitaires de France, Bruxelas/Paris.

ECO U., (1987) Arte e bellezza nell'estetica medievale, Bompiani, Milão.

HANSEN, J.A. (1987) Alegoria, Atual Editora Ltda., S. Paulo.

HUIZINGA, J. (1999) The Waning of the Middle Ages, Dover Publications Inc., Mineola, N. York. s/t.

LAUSBERG, H. (1967) Elementos de retórica literária, Fundação Calouste Gulbenkian, Lisboa, $2^{\mathrm{a}}$ ed., trad., prefácio e aditamentos de R. M. Rosado Fernandes.

LUKÁCS, G., (1970) Estetica, vol. II, Giulio Einaudi ed., Torino, trad. Anna Marietti Solmi, cap. "Allegoria e simbolo”, pp. 1473-1516.

RICOEUR P. (1975) La Métaphore vive, Éditions du Seuil, Paris.

ZUMTHOR, P., (1972) Essai de poétique médiévale, Éditions du Seuil, Paris. 